\title{
○equestáo
}

\section{Análise da participação das mulheres na ciência: um estudo de caso da área de Ciências Exatas e da Terra no Brasil}

\author{
Esteban Fernandez Tuesta \\ Doutor; Universidade de São Paulo, São Paulo, SP, Brasil; \\ tuesta@usp.br \\ Luciano Antonio Digiampietri \\ Doutor; Universidade de São Paulo, São Paulo, SP, Brasil; \\ digiampietri@usp.br \\ Karina Valdivia Delgado \\ Doutora; Universidade de São Paulo, São Paulo, SP, Brasil; \\ kvd@usp.br \\ Nathália Ferraz Alonso Martins \\ Mestranda; Universidade de São Paulo, São Paulo, SP, Brasil; \\ nfamartins@gmail.com
}

\begin{abstract}
Resumo: Há várias décadas, estudos sobre a presença das mulheres na ciência são realizados e servem para identificar a sua participação e produção, como também são usados de base para o desenvolvimento de políticas científicas de incentivo e valorização feminina na ciência. O presente trabalho avaliou a produção científica de mais de 40 mil doutoras e doutores brasileiros que atuam na área de Ciências Exatas e da Terra e concluiu que: (1) a participação de homens é consideravelmente maior que a de mulheres em praticamente todas as subáreas analisadas; (2) existe um crescimento na presença das mulheres ao longo do tempo; e (3) a porcentagem de publicações de mulheres é levemente inferior em relação à porcentagem de sua participação.
\end{abstract}

Palavras-chave: Mulheres na ciência. Produção científica. Ciências Exatas e da Terra.

\section{Introdução}

Estudos sobre a temática "participação das mulheres na ciência" têm chamado a atenção de um considerável número de pesquisadores há algumas décadas, e o número de trabalhos relacionados tem crescido de maneira constante ao longo dos anos. As abordagens para o tema "mulheres na ciência" são interdisciplinares e apresentam peculiaridades dependendo da área de atuação, da região geográfica, das fontes utilizadas e dos objetivos traçados pelos 

ciência: um estudo de caso da área de Ciências Exatas e da Terra no Brasil

Esteban Fernandez Tuesta, Luciano Antonio Digiampietri, Karina Valdivia Delgado e Nathália Ferraz Alonso Martins

pesquisadores. No trabalho escrito por Leta (2014), a autora faz uma ampla revisão dos artigos que abordam esse assunto, incluindo aqueles que focam os aspectos psicológicos, sociológicos, históricos e biológicos.

Uma grande parte desses estudos, sob o olhar dos distintos campos de conhecimento, procura respostas para a pergunta: existem diferenças entre a produtividade científica feminina e masculina? (LETA, 2014). O assunto das diferenças parece ser antigo, e, embora pesquisas tenham demonstrado que a participação das mulheres na ciência tem crescido ao longo do tempo, assim como sua produtividade, o gender gap - descrito pelos autores Xie e Shauman (1998) como a diferença entre a produção de homens e mulheres - ainda é investigado. Segundo eles, esse problema, também conhecido como productivity puzzle, está associado a um outro problema, que denominam career puzzle: a dificuldade de permanência das mulheres na academia em condições iguais às de seus pares homens (XIE; SHAUMAN, 1998).

A maior parte dos autores considera que publicações científicas e patentes desenvolvidas são os principais resultados da atividade científica e, portanto, podem ser utilizadas para medir o desempenho e produtividade (WEBSTER, 2001; AQUINO, 2006; MAULEÓN; BORDONS; OPPENHEIM, 2008; FERREIRA et al., 2008; FILIPPO; CASADO; GÓMEZ, 2009; BARRIOS; VILLARROYA; BORREGO, 2013). Outras abordagens consideram instrumentos de avaliação associados às publicações científicas como medida de produtividade, entre eles o Fator de Impacto (FI) das revistas nas quais os resultados foram publicados e o número de citações recebidas durante um período de tempo. Uma abordagem alternativa para essa investigação utiliza o Curriculum Vitae (CV) de cientistas para realizar análises bibliométricas (SANDSTRÖM, 2009; CAÑIBANO SÁNCHEZ; BOZEMAN, 2009).

Apesar da importância do objeto de estudo, ainda existem diversas dificuldades para a realização desse tipo de pesquisa. Em Mauleón, Bordons e Oppenheim (2008), os autores relatam a falta de trabalhos prévios que forneçam uma metodologia padrão, e Kyvik e Teigen (1996), Webster (2001), Mauleón, Bordons, Oppenheim (2008) e Leta (2014) informam a dificuldade de 

ciência: um estudo de caso da área de Ciências Exatas e da Terra no Brasil

Esteban Fernandez Tuesta, Luciano Antonio Digiampietri, Karina Valdivia Delgado e Nathália Ferraz Alonso Martins

identificação de pesquisadores homens e mulheres nos bancos de dados disponíveis. O problema de identificação ocorre pela falta de indicação do usuário/pesquisador no banco de dados ou até mesmo pela ausência de tal campo nos sistemas de cadastro. Esse problema normalmente é contornado pela inferência a partir do nome do autor indicado nas publicações, mas esse método pode encontrar obstáculos, como a existência de nomes comuns tanto a homens quanto a mulheres ou o fato de que muitas revistas científicas não apresentam o nome completo dos autores, registrando apenas as iniciais dos seus nomes. Parte dessa dificuldade é superada em países como Polônia e Islândia, nos quais é possível identificar se o nome é masculino ou feminino a partir do sobrenome (WEBSTER, 2001; LEWISON, 2001; Mauleón; Bordons; Oppenheim, 2008). Outra dificuldade está relacionada ao tamanho da amostra e ao intervalo de tempo pequeno da maioria das análises (WEBSTER, 2001; BARRIOS; VILLARROYA; BORREGO, 2013).

$\mathrm{O}$ presente trabalho considera os dados contidos nos $\mathrm{CV}$ dos pesquisadores doutores da área de Ciências Exatas e da Terra cadastrados na Plataforma Lattes (CONSELHO NACIONAL DE DESENVOLVIMENTO CIENTÍFICO E TECNOLÓGICO, 2018), o banco de dados mais completo dos pesquisadores brasileiros. O uso desse banco de dados oferece algumas vantagens em relação às fontes utilizadas nos trabalhos citados anteriormente: a primeira, a variável "sexo" do pesquisador está totalmente identificada para a maior parte dos currículos no banco; a segunda, os próprios autores cadastram suas publicações na plataforma, inclusive trabalhos que não estão indexados na Science Citation Index (SCI) nem publicados em periódicos com fator de impacto. Nesse banco, a área de Ciências Exatas e da Terra é composta por oito subáreas: Astronomia, Ciência da Computação, Física, Geociências, Matemática, Oceanografia, Probabilidade e Estatística e Química. Essas subáreas também são consideradas neste estudo.

O objetivo principal deste estudo é identificar e comparar a participação (entendida como a proporção da produção de artigos em revistas científicas) das mulheres brasileiras da área de Ciências Exatas e da Terra, assim como verificar 
se essa segue a tendência de crescimento encontrada em estudos realizados em outros países (XIE; SHAUMAN, 1998; WEBSTER, 2001; SYMONDS et al., 2006; ALONSO-ARROYO et al., 2010; BARRIOS; VILLARROYA; BORREGO, 2013; CESI et al., 2014). A importância do presente trabalho reside em dois principais aspectos: o estudo de um subgrupo da ciência, em que existe uma participação majoritariamente masculina não somente no Brasil, mas também em outros países (CESI, 2014), e o estudo da influência que exercem as publicações científicas na carreira acadêmica, principalmente nas áreas de Ciências Exatas (ARRUDA et al., 2009; CESI et al., 2014; SHELTZER; SMITH, 2014).

\section{Trabalhos relacionados}

O número de trabalhos sobre o assunto "mulheres na ciência" é abundante tanto no âmbito brasileiro quanto internacional. Nesta seção, apenas um pequeno grupo deles é citado, enfocando em alguns aspectos relacionados à presente abordagem.

Cesi et al. (2014) estudam o productivity puzzle, considerando dados da National Science Foundation (NSF) dos Estados Unidos e procurando identificar os fatores que promovem diferenças. Os autores consideram, entre outras, as diferenças entre os efeitos das aspirações familiares em homens e mulheres, as diferenças entre a presença de crianças nas carreiras de homens e mulheres e os resultados na produtividade, remuneração e produção. Neste trabalho, os autores estudam as diferenças em áreas espacial e matematicamente intensivas (Geociências, Engenharia, Economia, Matemática, Ciência da Computação, Química e Física), nas quais as mulheres estão sub-representadas, e áreas como Ciências da Vida, Psicologia e Ciências Sociais, em que existe uma paridade ou até um número de mulheres que excede o de homens. Os resultados indicam que as mulheres estão sub-representadas, especialmente entre os pesquisadores mais produtivos em áreas de conteúdo matemático intensivo, e que a diferença de 

ciência: um estudo de caso da área de Ciências Exatas e da Terra no Brasil

Esteban Fernandez Tuesta, Luciano Antonio Digiampietri, Karina Valdivia Delgado e Nathália Ferraz Alonso Martins

produtividade decresceu para ambos os campos até a metade dos anos 90, estabilizando-se em seguida.

Um importante projeto em andamento no Brasil. denominado Parent in science, visa a discutir e estudar a maternidade e seus efeitos na ciência no Brasil (PARENT IN SCIENCE, 2018). Esse projeto conta com a participação de um grande número de pesquisadores de diversas atividades científicas do Brasil e do exterior.

No artigo de Alonso-Arroyo et al. (2010) é realizada uma análise da produção científica das docentes universitárias em Ciências da Saúde da Comunidade Valenciana, na Espanha, durante o período de 2003 a 2007, identificando um crescimento não somente na participação, mas também na produção científica do grupo analisado, especialmente na parcela de pesquisadores com número consideravelmente maior de artigos.

Leta (2014) analisa os dados da produção científica brasileira em três campos da ciência - Astronomia, Imunologia e Oceanografia - entre o período de 1997 a 2001, apontando que as diferenças entre o desempenho de homens e mulheres estão relacionadas principalmente com a presença relativa deles no campo e com o recorte dado às análises.

Arruda et al. (2009) realizam uma análise sobre a participação das mulheres na área de Ciência da Computação. Nela, os autores identificaram que: (I) apesar do baixo número de pesquisadoras mulheres na Ciência da Computação no Brasil, elas aparecem em maior proporção em subáreas em que, de acordo com os autores, o "componente humano" é mais importante, tais como: Inteligência Artificial, Sistemas Colaborativos, Computação na Educação e Interface Homem-Máquina; e (II) elas participam menos em subáreas nas quais os mesmos autores indicam que o "componente tecnológico" se sobressai, tais como Hardware e Redes. É visto ainda que, naquelas subáreas em que as mulheres aparecem em proporção maior do que a da razão geral, elas são mais produtivas que os homens. 

ciência: um estudo de caso da área de Ciências Exatas e da Terra no Brasil

Esteban Fernandez Tuesta, Luciano Antonio Digiampietri, Karina Valdivia Delgado e Nathália Ferraz Alonso Martins

Um estudo recente, que investiga a sub-representatividade das mulheres nos níveis mais altos da ciência brasileira (VALENTOVA et al., 2017), analisa o gender gap entre os anos 2013 e 2014 a partir de três fontes bem documentadas: os bolsistas do Conselho Nacional de Desenvolvimento Científico e Tecnológico (CNPq), os membros da Academia Brasileira de Ciências (ABC) e a quantidade de auxílios à pesquisa recebidos na chamada universal do CNPq. Os autores analisam as diferenças de níveis de financiamento para três grupos: o primeiro contém as subáreas de Engenharia e Ciências Exatas e da Terra; o segundo, as subáreas de Ciências da Vida; e o terceiro, as subáreas de Humanidades e Ciências Sociais. Os resultados apontam que existe uma desigualdade na concessão de auxílios, ou seja, as mulheres têm valores de fomento à pesquisa mais baixos do que seus pares homens para as áreas de Engenharia, Ciências Exatas e da Terra e Ciências da Vida; já para Humanidades e Ciências Sociais Aplicadas, essa diferença não é observada nos detentores de bolsas de produtividade 1A e 1B.

De maneira semelhante a alguns dos artigos acima descritos, o presente estudo foca em algumas subáreas de conteúdo espacial e matematicamente intensivos, incluindo Astronomia, Ciência da Computação, Física, Geociências, Matemática, Oceanografia, Probabilidade e Estatística e Química.

\section{Materiais e métodos}

Os dados analisados neste artigo foram extraídos da plataforma de currículos Lattes. Cada CV foi identificado e armazenado numa base de dados relacional, discriminando-se as caraterísticas necessárias para o estudo. Os dados de cada pesquisador selecionado são: código de identificação, sexo, publicações em periódicos por ano, ano de início e de conclusão do doutorado e número de autores de cada publicação. Foram consideradas apenas as publicações entre os anos 1966 e 2015, com o objetivo de realizar análises detalhadas da evolução da participação e produção das mulheres. Os pesquisadores foram divididos em 
grupos de acordo com o ano de início do doutorado (1966 a 1975, 1976 a 1985, 1986 a 1995, 1996 a 2005 e 2006 a 2015).

Foram encontrados 40.882 pesquisadores com início de doutorado entre os anos 1966 e 2015, registrados na área de Ciências Exatas e da Terra como principal área de atuação e com a variável "sexo" identificada. Destaca-se que, apesar da plataforma ter sido criada na década de 80, os pesquisadores preencheram as suas atividades e produção científica de maneira retroativa. A soma do número de pesquisadores por subáreas é 46.977, número maior do que os 40.882. A razão dessa diferença reside no fato de que alguns indivíduos colocaram no currículo atuação em duas ou mais subáreas.

$\mathrm{Na}$ amostra, foram identificados 27.334 homens $(66,86 \%)$ e 13.548 mulheres $(33,14 \%)$. A quantidade de homens e mulheres por subárea é mostrada na Tabela 1.

Tabela 1 - Porcentagem de indivíduos na amostra por gênero e subárea

\begin{tabular}{l|r|r}
\hline \multicolumn{1}{c|}{ Área e subáreas } & \multicolumn{1}{c}{ Homem } & \multicolumn{1}{c}{ Mulher } \\
\hline Ciências Exatas e da Terra & $27.334(66,86 \%)$ & $13.548(33,14 \%)$ \\
\hline Astronomia & $669(76,99 \%)$ & $200(23,01 \%)$ \\
\hline Física & $6.941(79,33 \%)$ & $1.809(20,67 \%)$ \\
\hline Ciências da Computação & $6.660(77,83 \%)$ & $1.897(22,17 \%)$ \\
\hline Matemática & $4.408(69,87 \%)$ & $1.901(30,13 \%)$ \\
\hline Probabilidade e Estatística & $2.161(69,40 \%)$ & $953(30,60 \%)$ \\
\hline Geociências & $4.254(66,03 \%)$ & $2.189(33,97 \%)$ \\
\hline Oceanografia & $906(58,08 \%)$ & $654(41,92 \%)$ \\
\hline Química & $5.850(51,43 \%)$ & $5.525(48,57 \%)$ \\
\hline \multicolumn{2}{c|}{ Fonte: Elaborado pelos autores. }
\end{tabular}

A amostra contém 705.623 registros de publicações em periódicos, dos quais $528.159(74,85 \%)$ foram cadastrados por homens e $177.464(25,15 \%)$, por mulheres (Tabela 2). É possível observar que, nesses valores, podem existir duplicações, já que a contagem foi realizada pela soma de publicações de cada indivíduo, ou seja, uma publicação com mais de um autor(a) foi contabilizada uma vez para cada autor(a) que a cadastrou na plataforma. As análises foram realizadas para a área de Ciências Exatas e da Terra e para cada uma de suas 

ciência: um estudo de caso da área de Ciências Exatas e da Terra no Brasil

Esteban Fernandez Tuesta, Luciano Antonio Digiampietri, Karina Valdivia Delgado e Nathália Ferraz Alonso Martins

subáreas, sendo outra vez observado o fenômeno da contagem duplicada pela presença de mais de um autor(a) em grande parte dos trabalhos e também pela presença de um mesmo autor(a) pertencente a duas ou mais subáreas.

Tabela 2 - Porcentagem de publicações na amostra por gênero e subárea

\begin{tabular}{|c|c|c|c|c|}
\hline \multirow[t]{2}{*}{ Área e subáreas } & \multicolumn{2}{|c|}{$\begin{array}{l}\text { Quantidade de } \\
\text { publicações }\end{array}$} & \multicolumn{2}{|c|}{$\begin{array}{c}\text { Diferença entre produção } \\
\text { e participação }(\%)\end{array}$} \\
\hline & Homens & Mulheres & Homens & Mulheres \\
\hline $\begin{array}{l}\text { Ciências Exatas e } \\
\text { da Terra }\end{array}$ & $\begin{array}{r}528.159 \\
(74,85 \%)\end{array}$ & $\begin{array}{r}177.464 \\
(25,15 \%)\end{array}$ & 7,99 & $-7,99$ \\
\hline Astronomia & $\begin{array}{r}17.241 \\
(84,72 \%)\end{array}$ & $\begin{array}{r}3.110 \\
(15,28 \%)\end{array}$ & 7,73 & $-7,73$ \\
\hline Física & $\begin{array}{r}186.488 \\
(84,65 \%)\end{array}$ & $\begin{array}{r}33.818 \\
(15,35 \%)\end{array}$ & 5,32 & $-5,32$ \\
\hline $\begin{array}{l}\text { Ciência da } \\
\text { Computação }\end{array}$ & $\begin{array}{r}69.595 \\
(82,09 \%)\end{array}$ & $\begin{array}{r}15.185 \\
(17,91 \%)\end{array}$ & 4,26 & $-4,26$ \\
\hline Matemática & $\begin{array}{r}53.154 \\
(80,66 \%)\end{array}$ & $\begin{array}{r}12.742 \\
(19,34 \%)\end{array}$ & 10,79 & $-10,79$ \\
\hline $\begin{array}{l}\text { Probabilidade e } \\
\text { Estatística }\end{array}$ & $\begin{array}{r}45.663 \\
(77,35 \%)\end{array}$ & $\begin{array}{r}13.372 \\
(22,65 \%)\end{array}$ & 7,95 & $-7,95$ \\
\hline Geociências & $\begin{array}{r}77.318 \\
(75,26 \%)\end{array}$ & $\begin{array}{r}25.414 \\
(24,74 \%)\end{array}$ & 9,23 & $-9,23$ \\
\hline Oceanografia & $\begin{array}{r}19.874 \\
(68,13 \%)\end{array}$ & $\begin{array}{r}9.297 \\
(31,87 \%)\end{array}$ & 10,05 & $-10,05$ \\
\hline Química & $\begin{array}{r}149.536 \\
(64,30 \%)\end{array}$ & $\begin{array}{r}83.038 \\
(35,70 \%)\end{array}$ & 12,87 & $-12,87$ \\
\hline
\end{tabular}

Fonte: Elaborado pelos autores.

\section{Resultados e discussão}

Com base nos dados analisados, identificou-se que a proporção de homens é consideravelmente maior que a de mulheres para quase todas as subáreas de Ciências Exatas e da Terra (acima de 32\% de diferença), com exceção de Química (diferença de 2,86\%) e Oceanografia (16,16\%), como pode ser observado na Tabela 1. Em Física, nota-se que a proporção de pesquisadoras é a menor das subáreas, sendo a diferença entre os gêneros superior a $58 \%$. Esses dados estão em concordância com os resultados de outros estudos realizados 

ciência: um estudo de caso da área de Ciências Exatas e da Terra no Brasil

Esteban Fernandez Tuesta, Luciano Antonio Digiampietri, Karina Valdivia Delgado e Nathália Ferraz Alonso Martins

tanto no Brasil como em outros países (LETA, 2014). Um teste chi-quadrado de associação foi aplicado utilizando o pacote estatístico R-project (2018), buscando verificar se as escolhas das subáreas independem da variável "sexo" (excluindo, obviamente, a grande área Ciências Exatas e da Terra). O valor "p" encontrado $(\mathrm{p}<0,05)$ indica que as diferenças nas escolhas das subáreas são significativas. Um novo teste de diferença de proporções foi aplicado para cada proporção de mulheres nas distintas subáreas, comparando-as com as proporções de mulheres para a área de Ciências Exatas e da Terra, e os resultados mostraram que apenas as Geociências apresentam um valor de " $p$ " superior a 0,05, indicando ser o único grupo que preserva a proporção da área.

A tabela 2 mostra que as mulheres têm diferença negativa entre participação e produção, indicando que a proporção de publicações é inferior à proporção de sua participação. Esses resultados também são consistentes com os encontrados na literatura (BRAISHER; SYMONDS; GEMMELL, 2005; SYMONDS et al., 2006; KELLY; JENNIONS, 2006; XIE; SHAUMAN, 1998). Com o objetivo de comparar as proporções de participação e produção, testes de diferença foram aplicados às proporções para todas as subáreas e inclusive para as proporções da área, e o valor de $\mathrm{p}$ encontrado em todos os casos é $\mathrm{p}<0,05$, indicando que a produtividade é estatisticamente menor do que a participação. Esses testes, apesar de consistentes com alguns dos resultados da literatura, foram realizados para o conjunto de dados totais, sem considerar o crescimento da participação e da produtividade das mulheres ao longo dos anos; dessa forma, um enfoque longitudinal seria necessário para descobrir se as diferenças foram encurtadas ou mantiveram-se. O modelo desse tipo de análise está em Tuesta e outros (2015).

A Figura 1 apresenta a distribuição de frequências das publicações de homens e mulheres, colocando no eixo vertical a proporção das publicações para os intervalos de classe (agrupamento de artigos) considerados para os indivíduos que iniciaram o doutorado entre 1976 e 1985 . Nesta figura, é possível observar que a proporção dos homens nas categorias de até 80 artigos é, em geral, semelhante ou menor do que a proporção das mulheres; por outro lado, nas 

ciência: um estudo de caso da área de Ciências Exatas e da Terra no Brasil

Esteban Fernandez Tuesta, Luciano Antonio Digiampietri, Karina Valdivia Delgado e Nathália Ferraz Alonso Martins

categorias acima de 80 artigos publicados, os homens apresentam a maior parcela, destacando-se entre os hiperprodutivos (aproximadamente 8\% dos homens publicaram mais de 130 artigos, contra 5\% das mulheres). Um resultado similar foi observado por Symonds et al. (2006) no grupo de pesquisadores da área de Biologia Evolucionária e Ecologia com primeiras publicações entre 1990 e 1993. Outro estudo recente sobre os pesquisadores sêniores no Brasil, de Valentova et al.(2017), mostra um resultado bastante semelhante, indicando a existência de um gender gap em algumas das áreas de investigação - entre elas, as Ciências Exatas.

Figura 1 - Porcentagem de publicações (início de doutorado entre 1976 e 1985)

Distribuição percentual das publicações

Ciências Exatas e da Terra (início de doutorado entre 1976 a 1985)

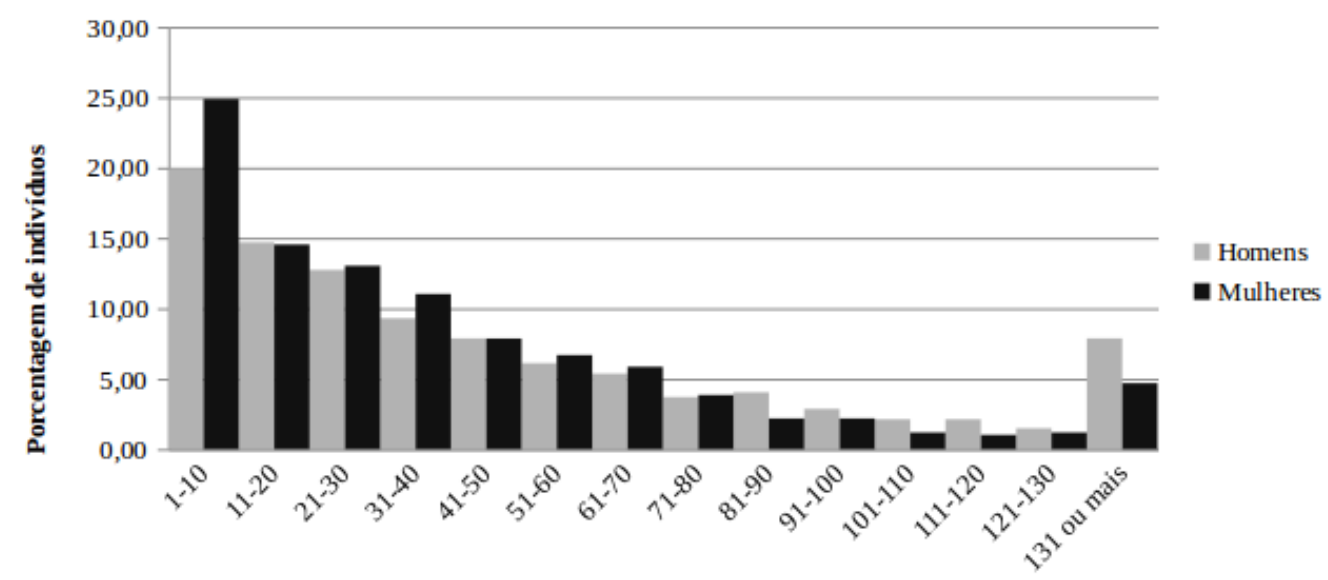

Número de publicações

Fonte: Elaborado pelos autores.

As Figuras 2 a 5 mostram a evolução da participação de homens e mulheres e de suas respectivas proporções na produção ao longo dos anos. Notase um decaimento da presença das mulheres de 1966 a meados de 1970 (de 26\% a $13 \%$, de $30 \%$ a $6 \%$, de $50 \%$ a $12 \%$, de $43 \%$ a $5 \%$ em Ciências Exatas e da Terra, Física, Oceanografia e Química, respectivamente). Desse ponto em diante, há um aumento de maneira geral até 2015, o ano final da análise realizada (até 31\%, 19\%, 37\% e 44\%, para Ciências Exatas e da Terra, Física, Oceanografia e Química, respectivamente). Esse resultado é consistente com o 

ciência: um estudo de caso da área de Ciências

Exatas e da Terra no Brasil

Esteban Fernandez Tuesta, Luciano Antonio Digiampietri, Karina Valdivia Delgado e Nathália Ferraz Alonso Martins

observado por Xie e Shauman (1998); tais incrementos são também observados em todas as outras subáreas do estudo. Entretanto, a produtividade das mulheres em relação à sua participação ainda é ligeiramente menor para Ciências Exatas e da Terra e suas subáreas.

Figura 2 - Evolução da proporção de publicações de homens e mulheres por ano (Ciências Exatas e da Terra) Ciências Exatas e da Terra

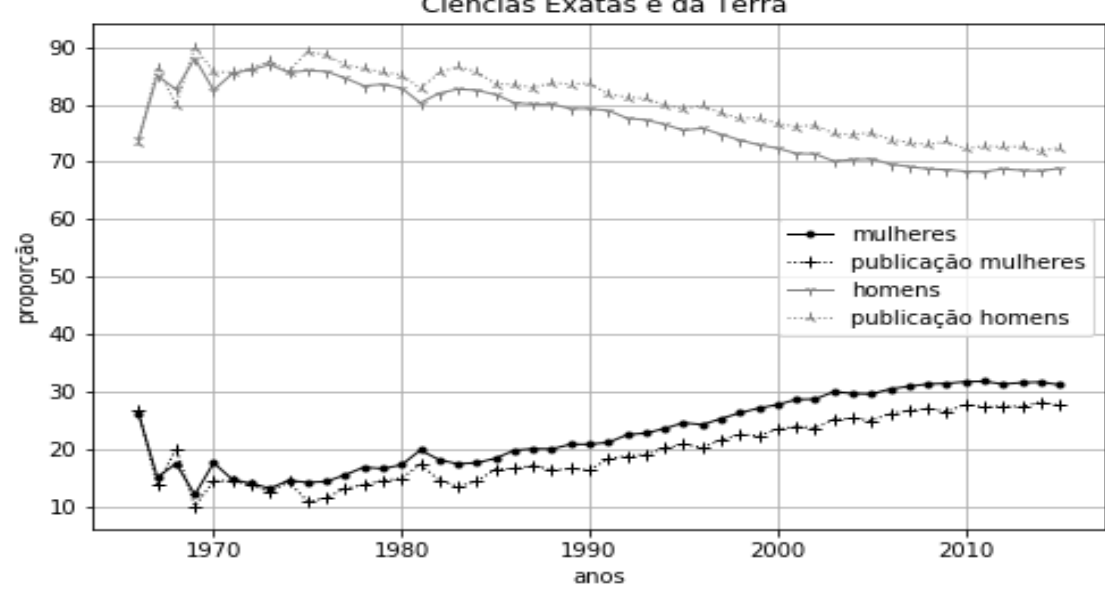

Fonte: Elaborado pelos autores.

Figura 3 - Evolução da proporção de publicações de homens e mulheres por ano (Física)

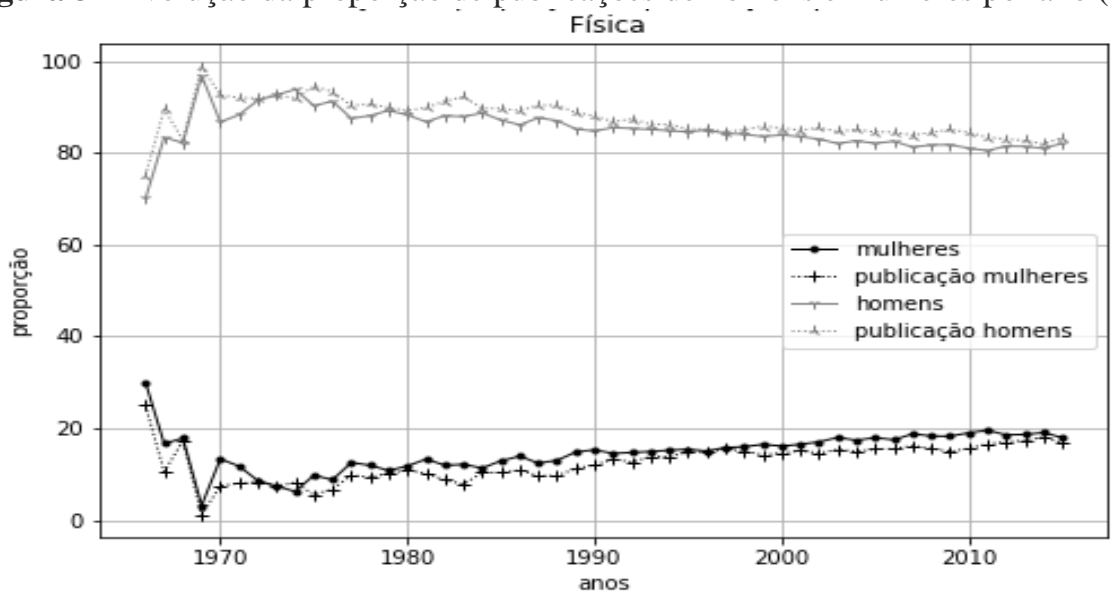

Fonte: Elaborado pelos autores. 

ciência: um estudo de caso da área de Ciências

Exatas e da Terra no Brasil

Esteban Fernandez Tuesta, Luciano Antonio Digiampietri, Karina Valdivia Delgado e Nathália Ferraz Alonso Martins

Figura 4 - Evolução da proporção de publicações de homens e mulheres por ano (Oceanografia)

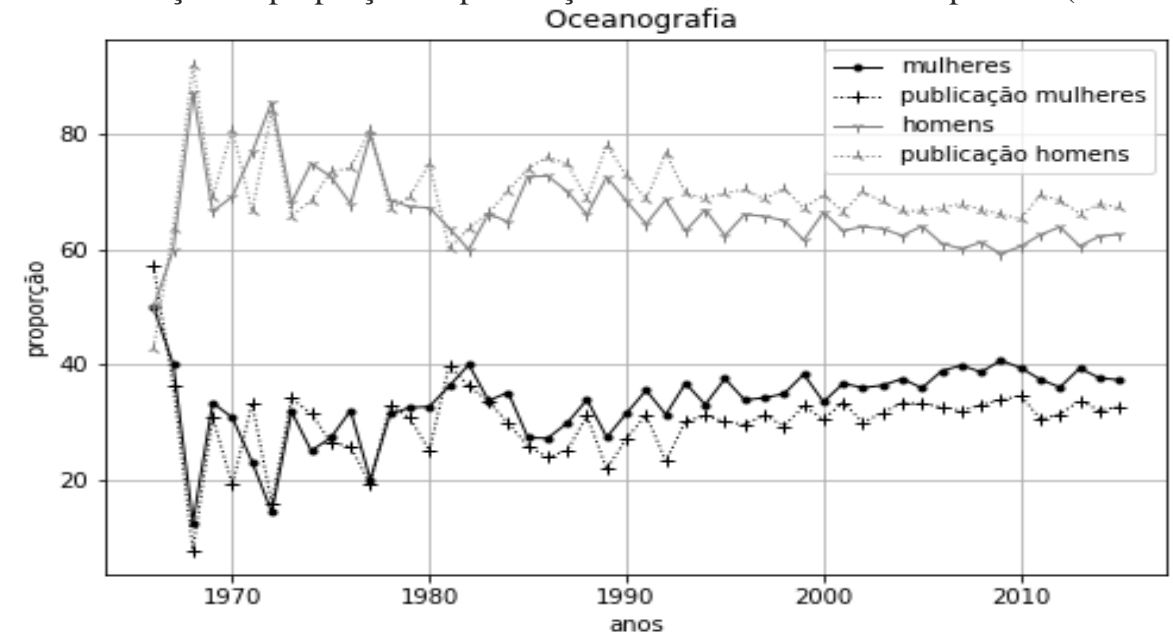

Fonte: Elaborado pelos autores.

Figura 5 - Evolução da proporção de publicações de homens e mulheres por ano (Química)

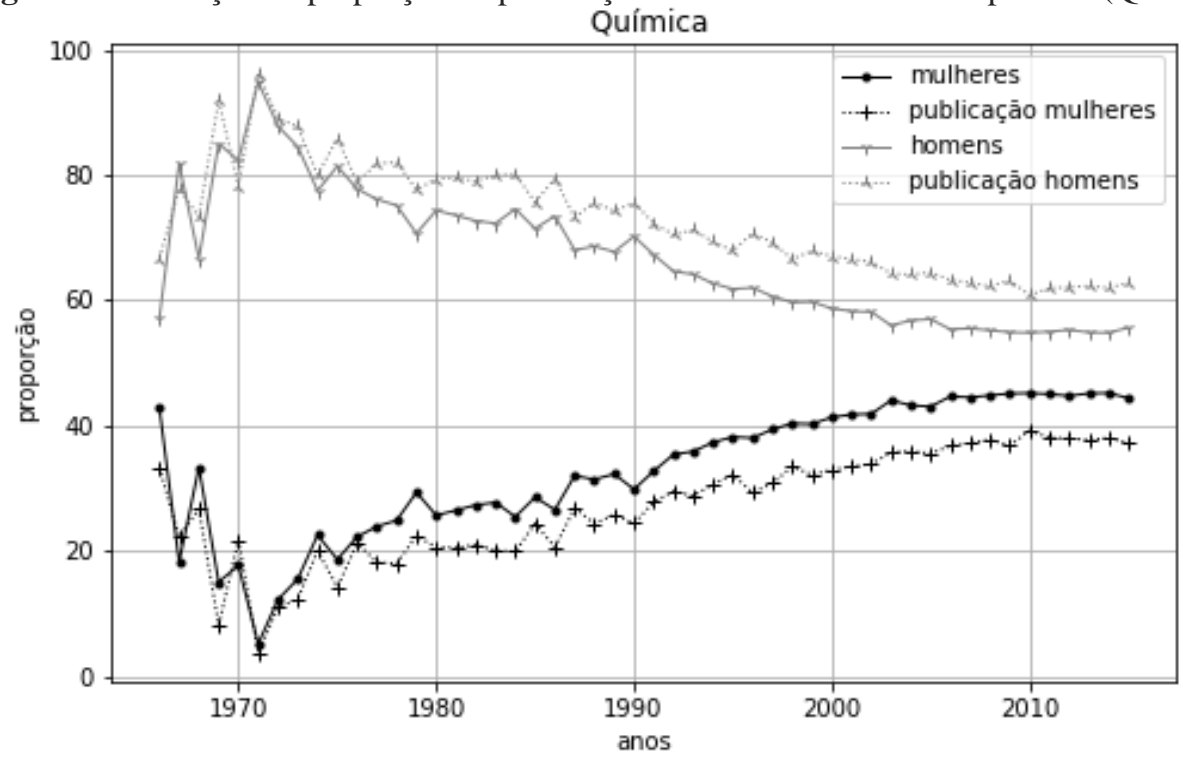

Fonte: Elaborado pelos autores.

Para estudar de maneira mais detalhada as diferenças entre a produtividade masculina e feminina, os pesquisadores foram divididos em cinco grupos de dez anos, de acordo com o ano de início do doutorado. O objetivo foi estudar e comparar as produtividades por gênero para indivíduos com o mesmo tempo de vida acadêmica (TUESTA et al., 2015). Os conjuntos escolhidos foram: ano de início de doutorado entre 1966 e 1975, entre 1976 e 1985, entre 1986 e 1995, entre 1996 a 2005 e entre 2006 e 2015. 
As Figuras 6 a 14 mostram a produtividade média anual de homens e mulheres das áreas de Ciências Exatas e da Terra (Figuras 6 a 10), Química (Figuras 11 e 12) e Física (Figuras 13 e 14). Nota-se que, nas três primeiras décadas (de 1966 a 1975, 1976 a 1985 e 1986 a 1995), logo no primeiro ano após o início de doutorado (ou seja, no segundo ano do doutorado), as médias das mulheres decresceram e diferenças significativas apareceram, o que corresponde provavelmente ao período que tangencia o fim do doutorado. Para outras subáreas, esse comportamento, no geral, foi mantido. As razões para esse pequeno atraso são desconhecidas, mas pode-se observar que, após um curto período de tempo, as curvas apresentam tendências positivas e muito próximas. Tal fenômeno também foi observado por Symonds e outros (2006). Esse decaimento inicial não foi observado nas duas últimas décadas (1996 a 2005 e 2006 a 2015). Nestas figuras, também é possível observar uma tendência ao decrescimento nas médias das publicações a partir dos 30 a 35 anos após o início do doutorado; uma possível explicação para esse fenômeno seria que o número de pesquisadores com mais de 35 anos de vida acadêmica é reduzida, seja pela sua aposentadoria ou por algum outro motivo não especificado.

Figura 6 - Média de produtividade anual de homens e mulheres (Ciências Exatas e da Terra)

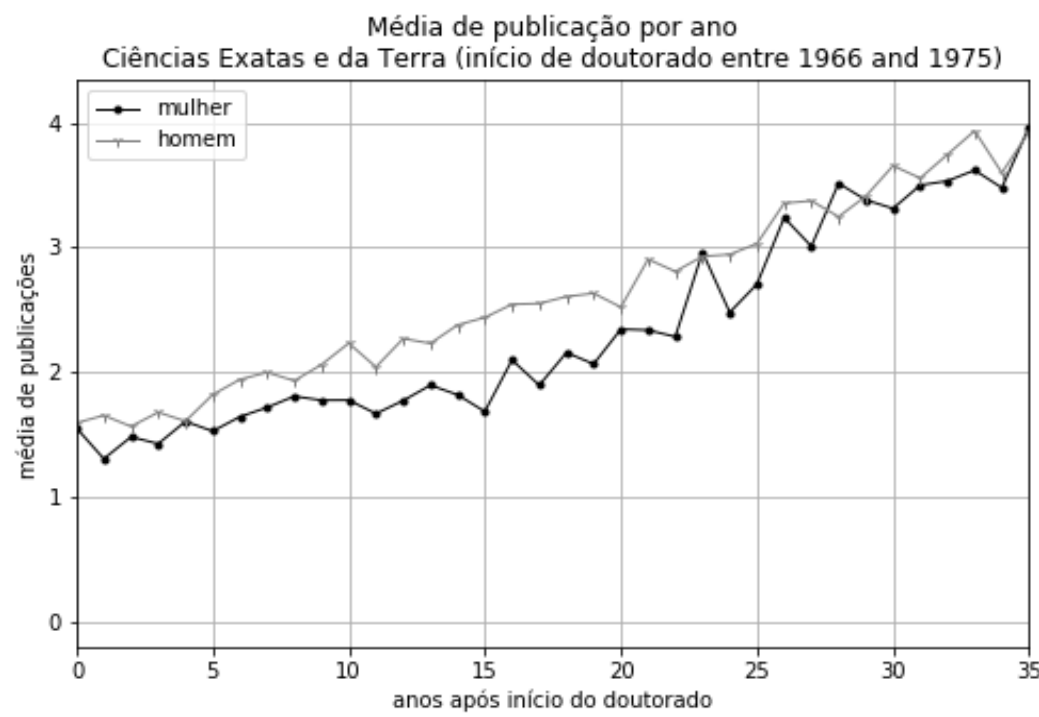

Fonte: Elaborado pelos autores. 

ciência: um estudo de caso da área de Ciências Exatas e da Terra no Brasil

Esteban Fernandez Tuesta, Luciano Antonio Digiampietri, Karina Valdivia Delgado e Nathália Ferraz Alonso Martins

Figura 7 - Média de produtividade anual de homens e mulheres (Ciências Exatas e da Terra)

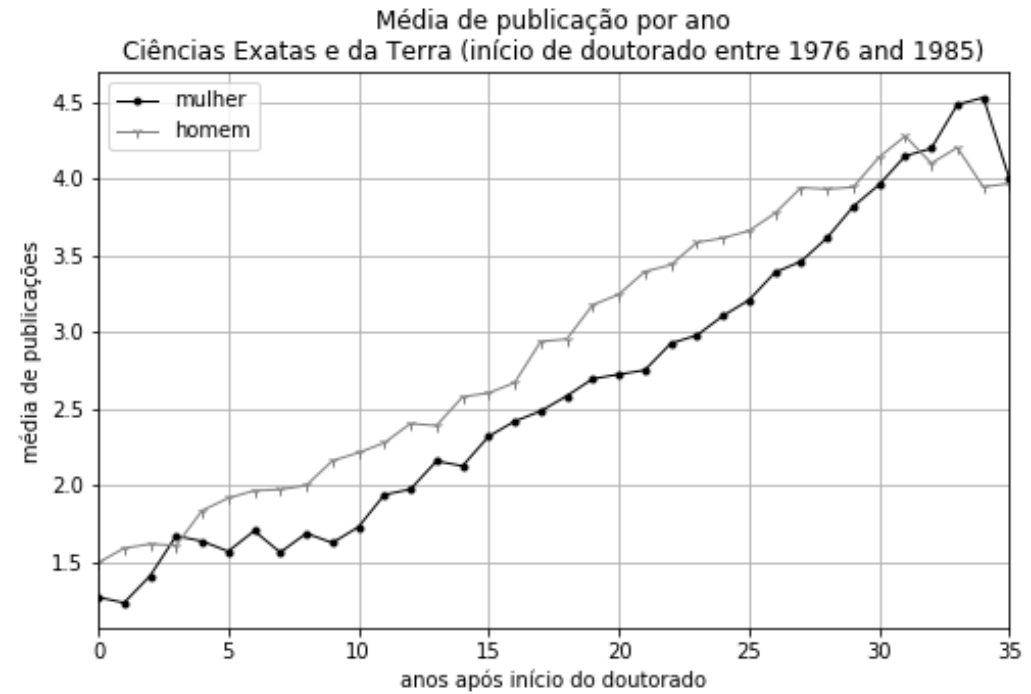

Fonte: Elaborado pelos autores.

Figura 8 - Média de produtividade anual de homens e mulheres (Ciências Exatas e da Terra)

Média de publicação por ano

Ciências Exatas e da Terra (início de doutorado entre 1986 and 1995)

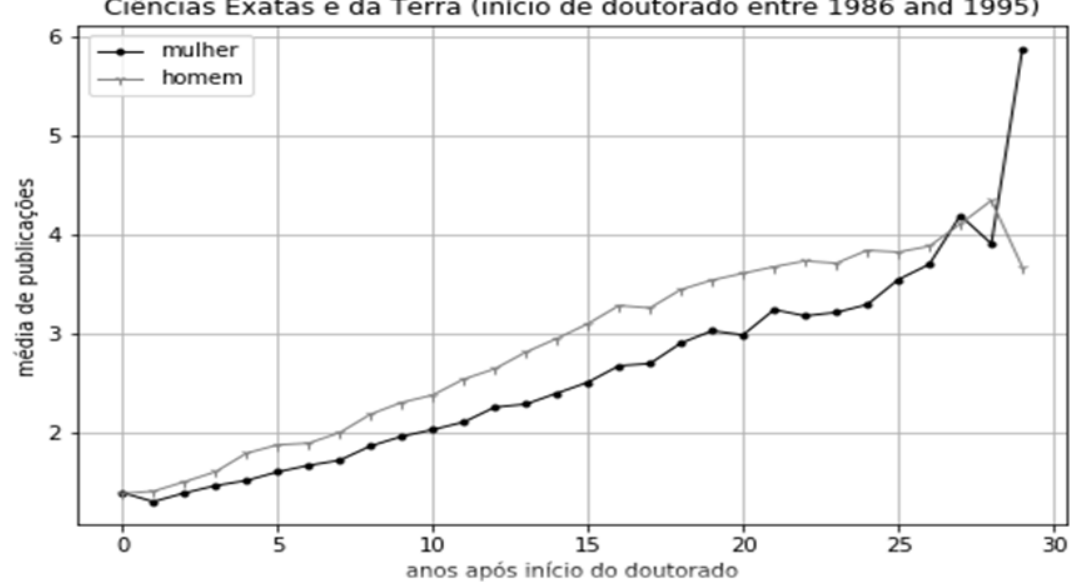

Fonte: Elaborado pelos autores.

Figura 9 - Média de produtividade anual de homens e mulheres (Ciências Exatas e da Terra)

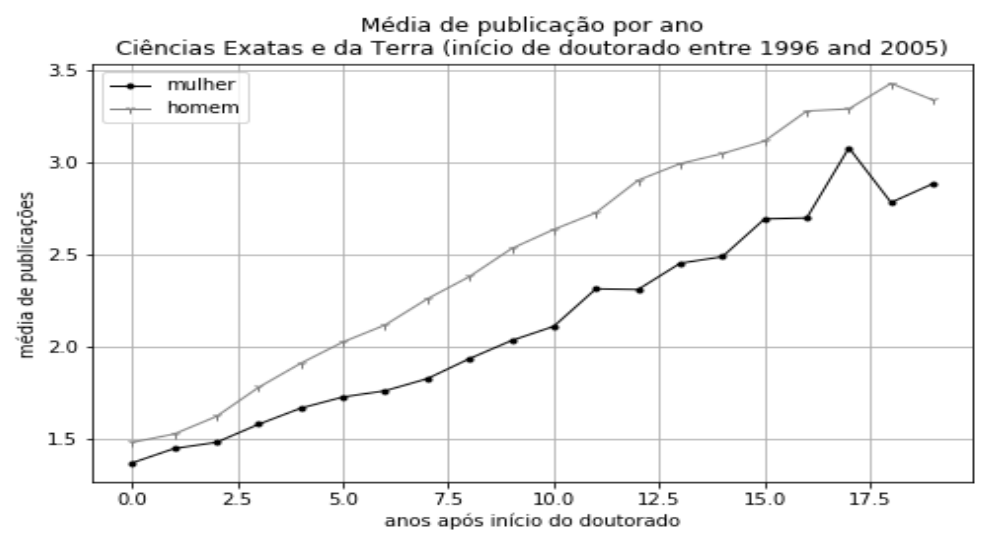

Fonte: Elaborado pelos autores. 

ciência: um estudo de caso da área de Ciências Exatas e da Terra no Brasil

Esteban Fernandez Tuesta, Luciano Antonio Digiampietri, Karina Valdivia Delgado e Nathália Ferraz Alonso Martins

Figura 10 - Média de produtividade anual de homens e mulheres (Ciências Exatas e da Terra)

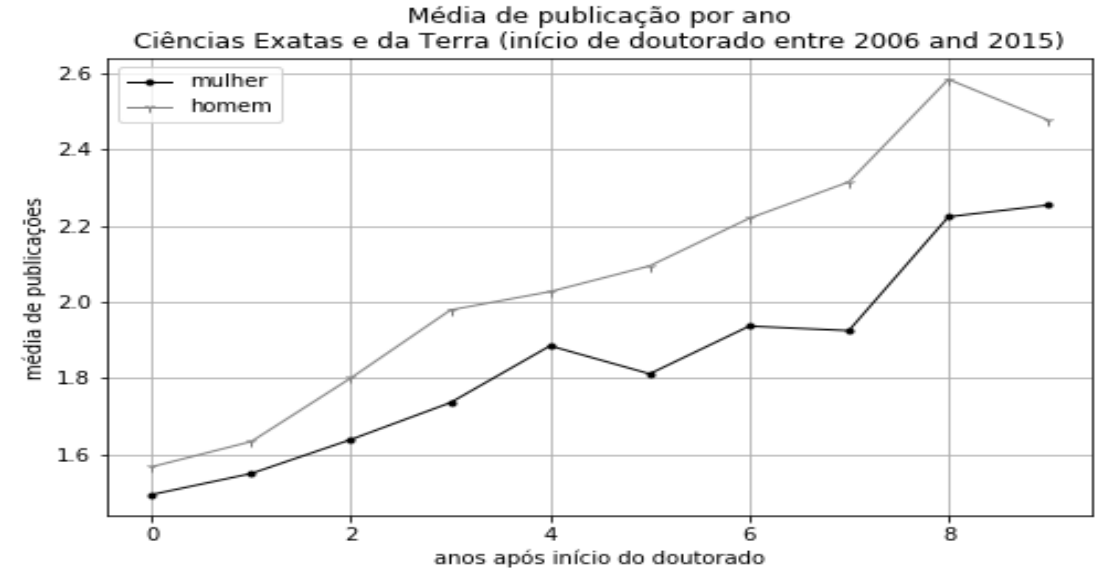

Fonte: Elaborado pelos autores.

Figura 11 - Média da produtividade anual de homens e mulheres (Química)

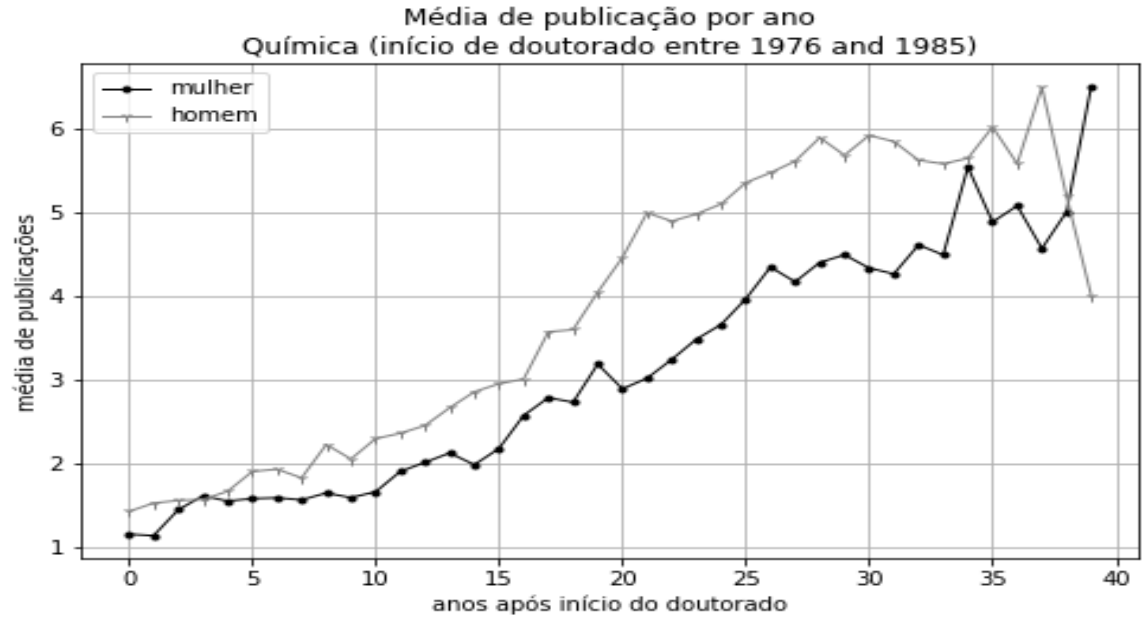

Fonte: Elaborado pelos autores.

Figura 12 - Média da produtividade anual de homens e mulheres (Química)

Média de publicação por ano

Química (início de doutorado entre 2006 and 2015)

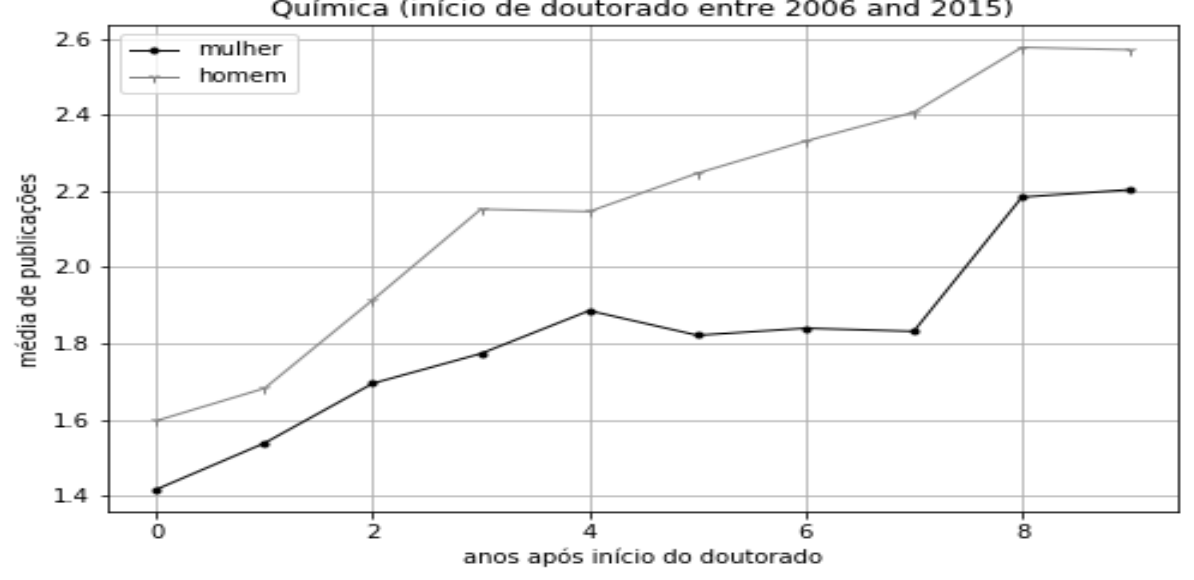

Fonte: Elaborado pelos autores. 
Figura 13 - Média da produtividade anual de homens e mulheres (Física)

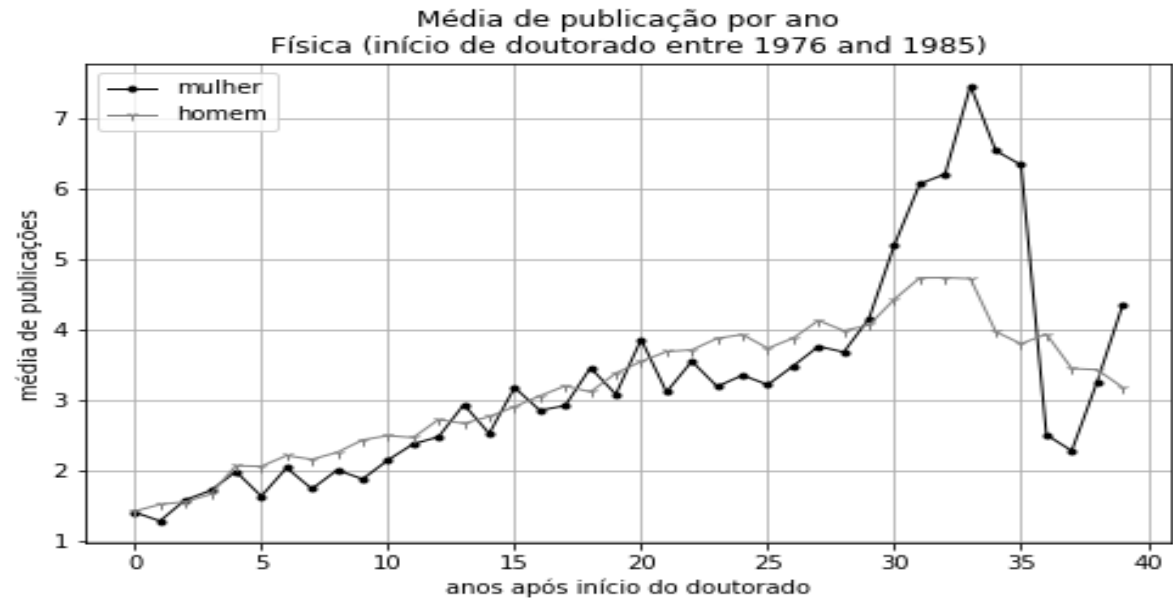

Fonte: Elaborado pelos autores.

Figura 14 - Média da produtividade anual de homens e mulheres (Física)

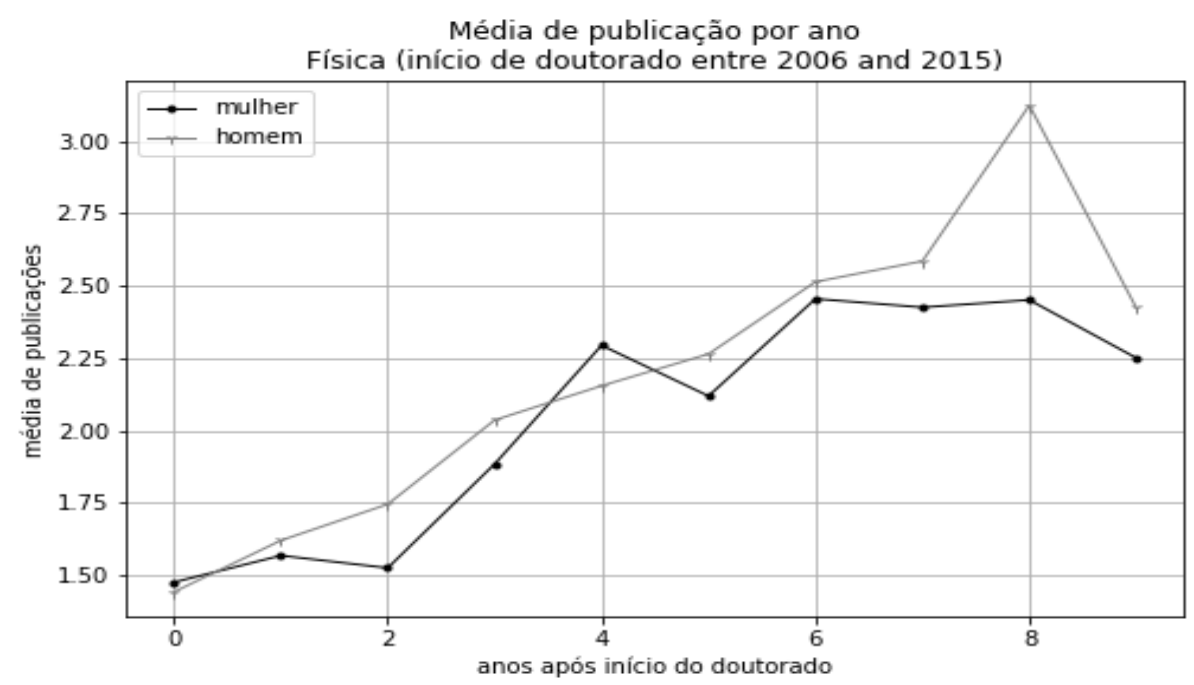

Fonte: Elaborado pelos autores.

Nas Figuras 15 a 18, é possível comparar o tempo médio para conclusão do doutorado em cada década analisada para as áreas de Ciências Exatas e da Terra (Figura 15), Oceanografia (Figura 16), Química (Figura 17) e Física (Figura 18). Nota-se um aumento acentuado da média entre as décadas de 1966 a 1975 e 1976 a 1985, tanto para mulheres quanto para homens. Em algumas áreas (como Ciência da Computação, Oceanografia e Geociências), a média de conclusão das mulheres na primeira década é ligeiramente superior à dos homens; para as demais décadas, as mulheres levam mais tempo do que os homens para finalizar o doutorado em todas as subáreas, exceto em Física na 

ciência: um estudo de caso da área de Ciências Exatas e da Terra no Brasil

Esteban Fernandez Tuesta, Luciano Antonio Digiampietri, Karina Valdivia Delgado e Nathália Ferraz Alonso Martins

última década (2006-2015), quando as mulheres alcançam a mesma média do que os homens (3,9 anos). Em todas as subáreas, o tempo de conclusão para homens e mulheres nas duas últimas décadas aproxima-se muito. Esse resultado pode ser explicado pelas novas regras estabelecidas pela Coordenação de Aperfeiçoamento de Pessoal de Nível Superior (CAPES), que coordena a avaliação dos programas de pós-graduação no Brasil. A agência estabeleceu um período máximo para que um aluno curse um programa de pós-graduação. Dessa forma, é esperado que o tempo médio de conclusão do doutorado diminua (TUESTA et al., 2015).

Figura 15 - Tempo médio de conclusão de doutorado de homens e mulheres por décadas (Ciências Exatas e da Terra)

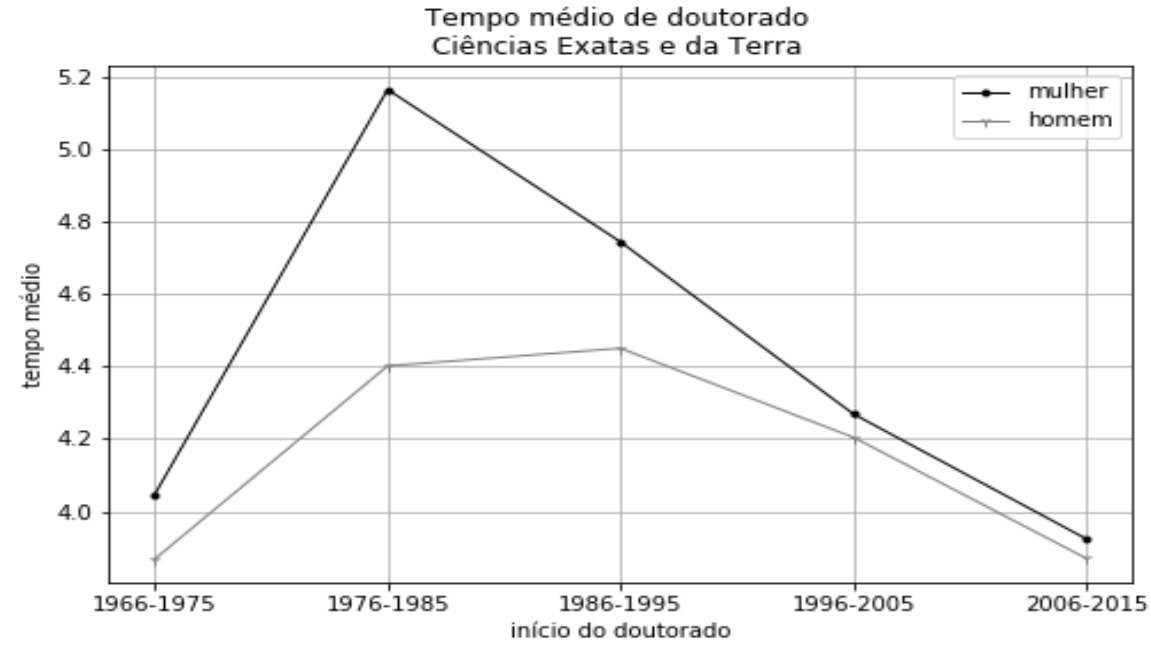

Fonte: Elaborado pelos autores.

Figura 16 - Tempo médio de conclusão de doutorado de homens e mulheres por décadas (Oceanografia)

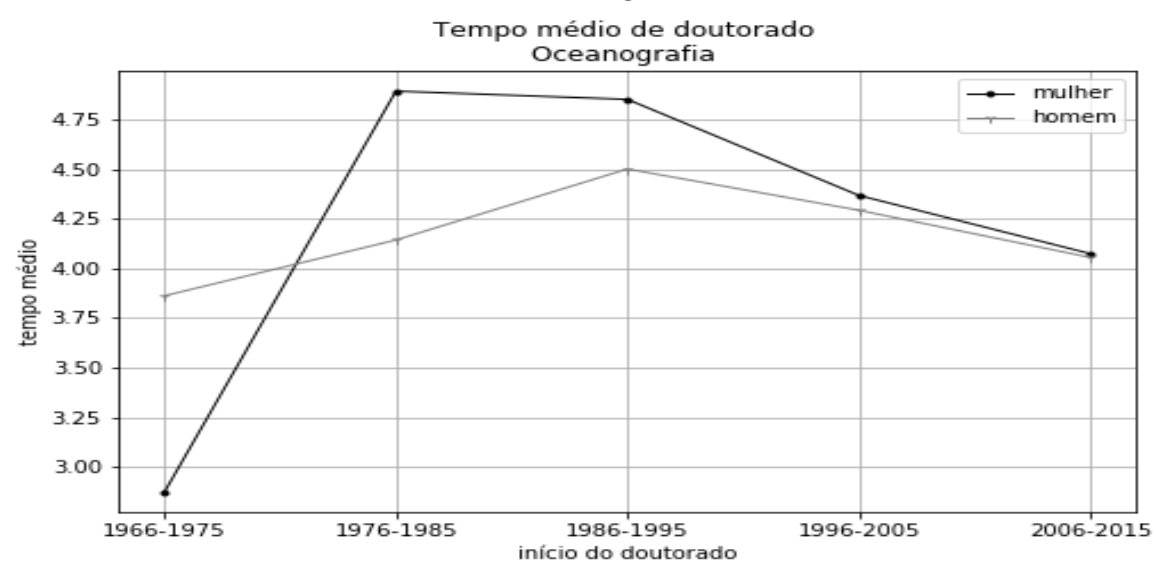

Fonte: Elaborado pelos autores. 

ciência: um estudo de caso da área de Ciências Exatas e da Terra no Brasil

Esteban Fernandez Tuesta, Luciano Antonio Digiampietri, Karina Valdivia Delgado e Nathália Ferraz Alonso Martins

Figura 17 - Tempo médio de conclusão de doutorado de homens e mulheres por décadas (Química)

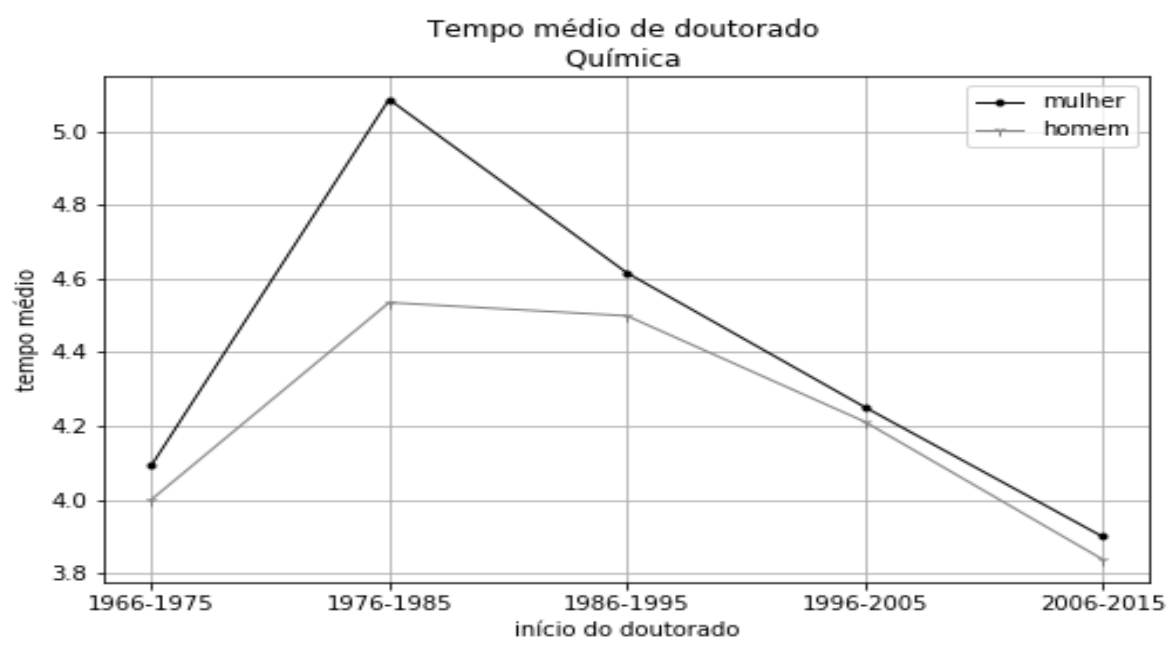

Fonte: Elaborado pelos autores.

Figura 18 - Tempo médio de conclusão de doutorado de homens e mulheres por décadas (Física)

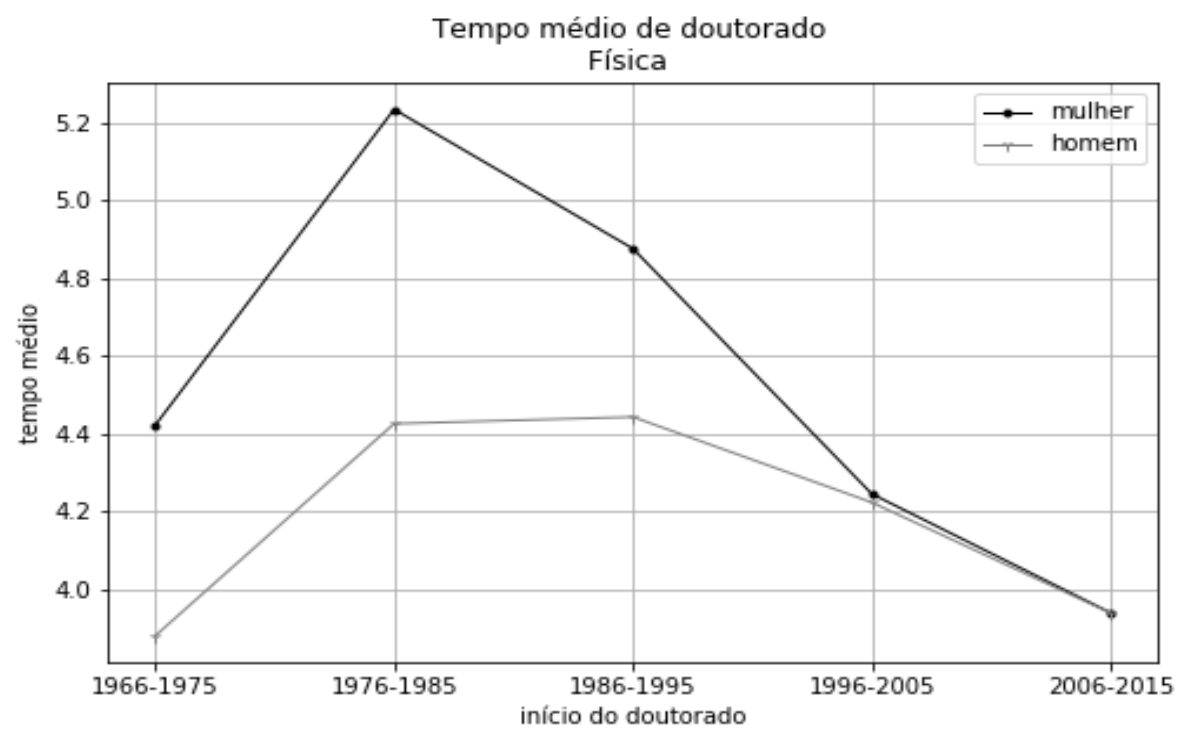

Fonte: Elaborado pelos autores.

As Figuras 19 a 27 apresentam dados de coautoria separados por década e gênero das áreas de Ciências Exatas e da Terra (Figuras 19 a 23), Química (Figuras 24 e 25) e Física (Figuras 26 e 27). De maneira geral, observa-se que homens e mulheres colaboram com mais pessoas com o passar do tempo e apresentam número médio de autores por artigo muito semelhantes, exceto em 

ciência: um estudo de caso da área de Ciências Exatas e da Terra no Brasil

Esteban Fernandez Tuesta, Luciano Antonio Digiampietri, Karina Valdivia Delgado e Nathália Ferraz Alonso Martins

alguns picos do gráfico, que podem ser justificados por artigos escritos em massa (grande quantidade de autores).

Uma interessante análise surge da comparação das Figuras 6, 11 e 13 com as Figuras 19, 24 e 26. Alguns picos de produtividade das mulheres são acompanhados de picos de quantidade de autores, por exemplo, como observado em Ciências Exatas e da Terra (década de 1986 a 1995, de 25 a 30 anos após o início do doutorado) e em Física (década de 1976 a 1985, de 30 a 35 anos após o início do doutorado).

Figura 19 - Média de autores por artigo de homens e mulheres por ano (Ciências Exatas e da Terra)

Média de autores por artigo por ano

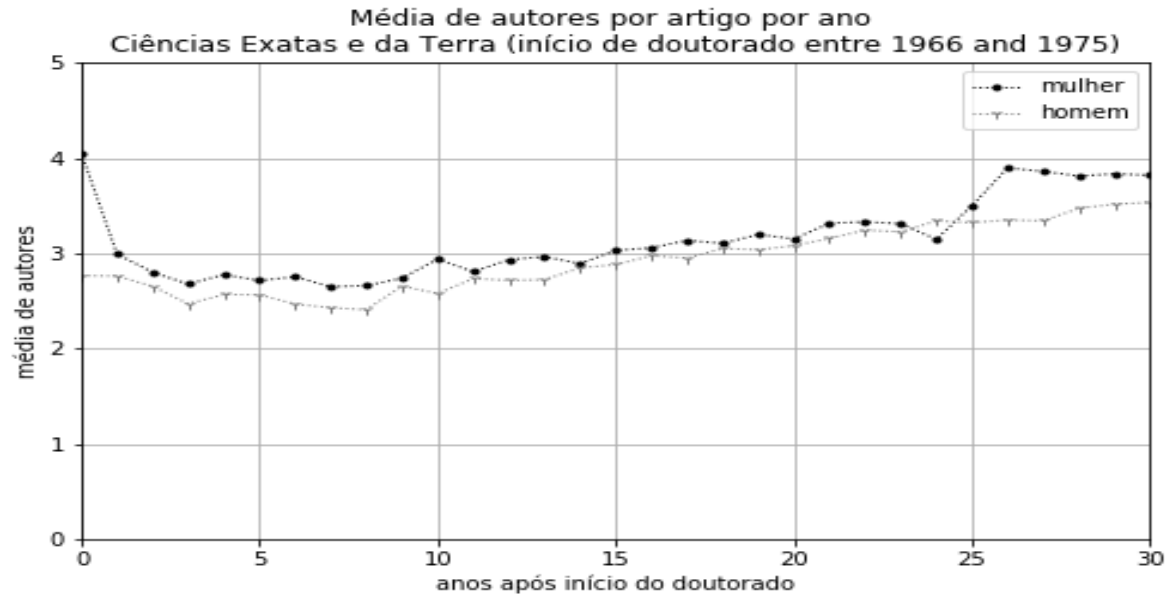

Fonte: Elaborado pelos autores.

Figura 20 - Média de autores por artigo de homens e mulheres por ano (Ciências Exatas e da Terra)

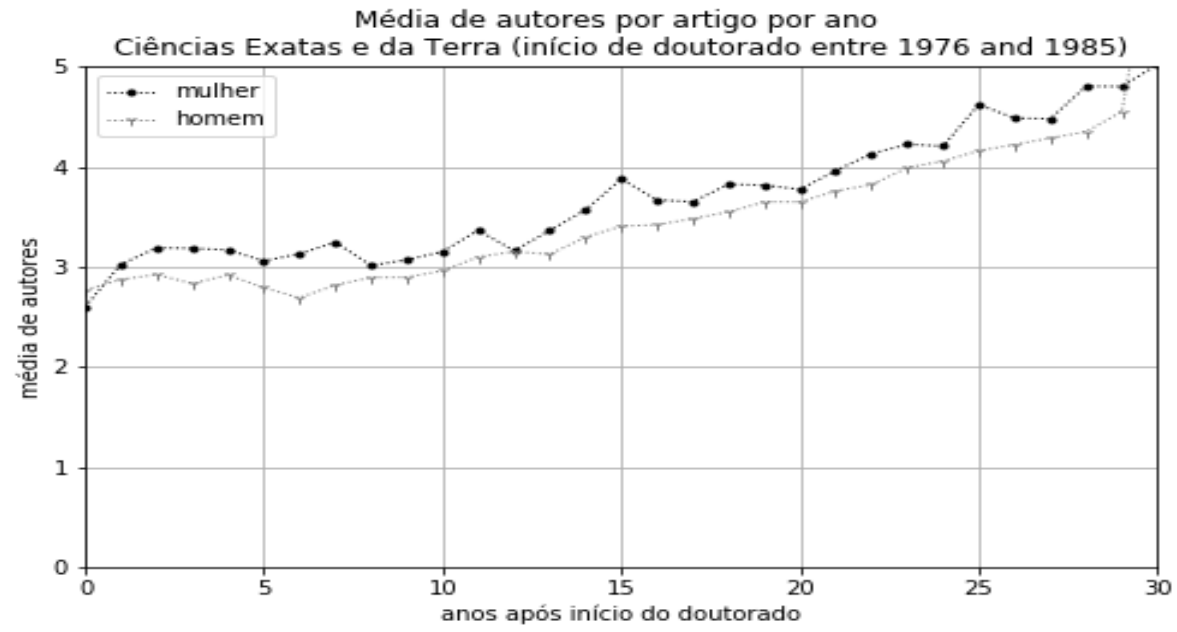

Fonte: Elaborado pelos autores. 

ciência: um estudo de caso da área de Ciências Exatas e da Terra no Brasil

Esteban Fernandez Tuesta, Luciano Antonio Digiampietri, Karina Valdivia Delgado e Nathália Ferraz Alonso Martins

Figura 21 - Média de autores por artigo de homens e mulheres por ano (Ciências Exatas e da Terra)

Média de autores por artigo por ano

Ciências Exatas e da Terra (início de doutorado entre 1986 and 1995)

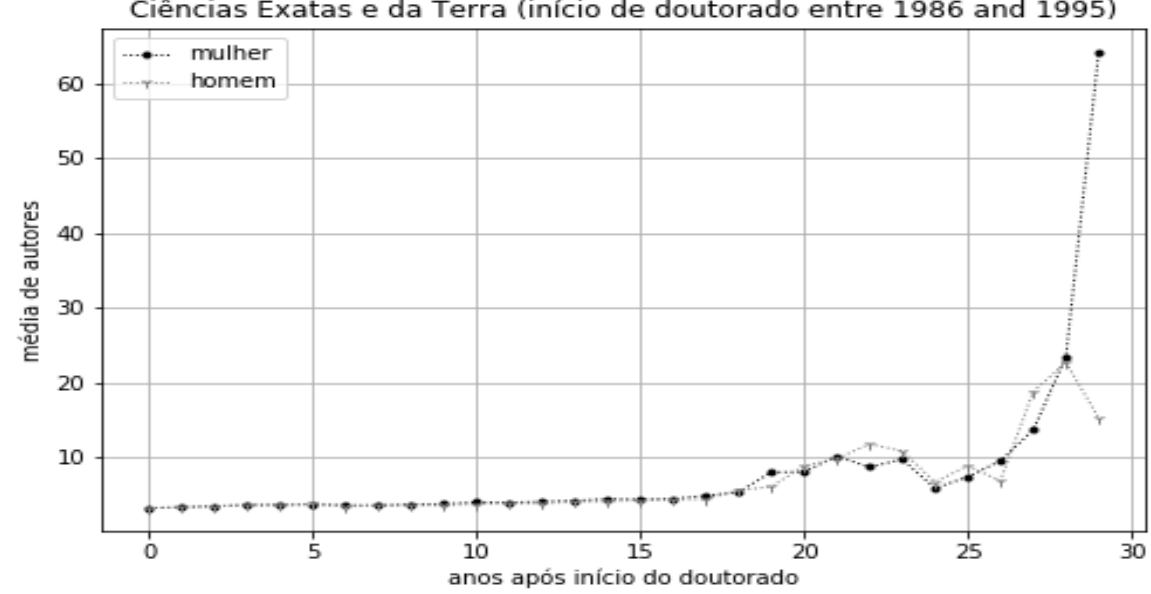

Fonte: Elaborado pelos autores.

Figura 22 - Média de autores por artigo de homens e mulheres por ano (Ciências Exatas e da Terra)

Média de autores por artigo por ano

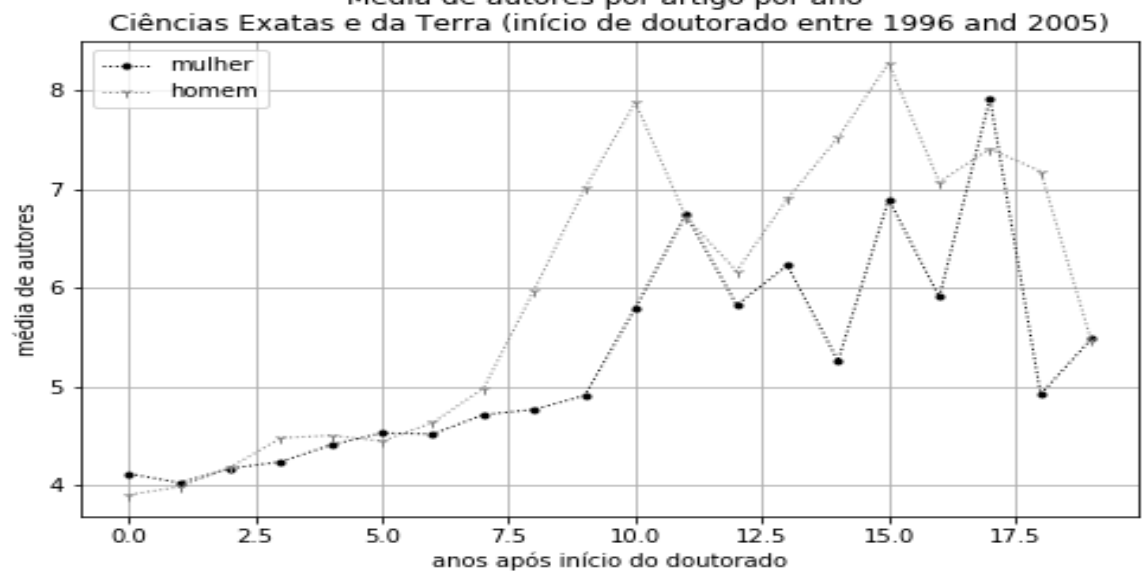

Fonte: Elaborado pelos autores.

Figura 23 - Média de autores por artigo de homens e mulheres por ano (Ciências Exatas e da Terra)

Média de autores por artigo por ano

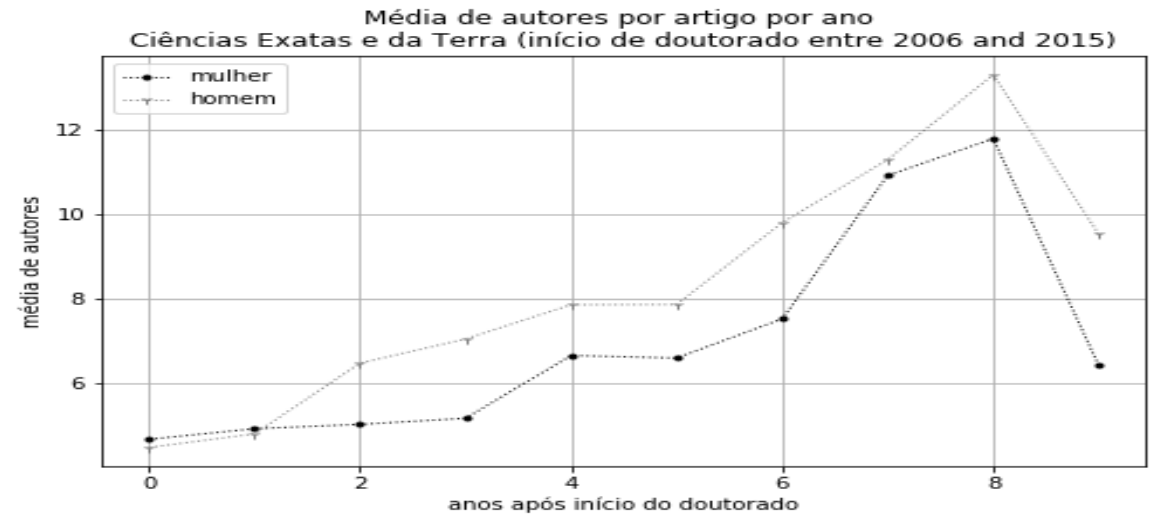

Fonte: Elaborado pelos autores. 

ciência: um estudo de caso da área de Ciências Exatas e da Terra no Brasil

Esteban Fernandez Tuesta, Luciano Antonio Digiampietri, Karina Valdivia Delgado e Nathália Ferraz Alonso Martins

Figura 24 - Média de autores por artigo de homens e mulheres por ano (Química)

Média de autores por artigo por ano Química (início de doutorado entre 1976 and 1985)

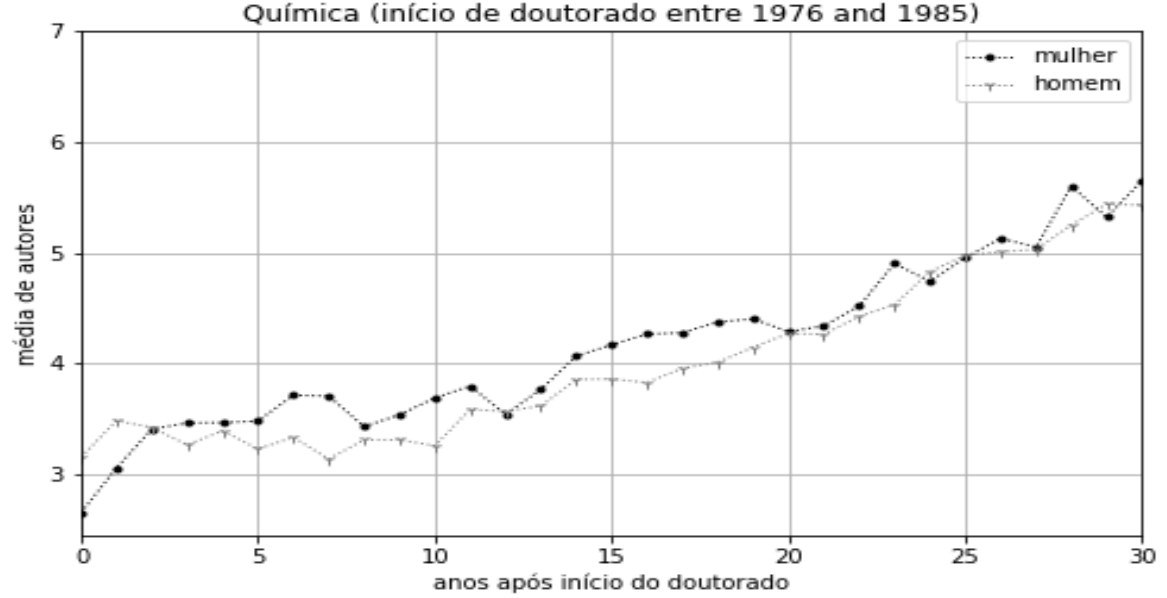

Fonte: Elaborado pelos autores.

Figura 25 - Média de autores por artigo de homens e mulheres por ano (Química)

Média de autores por artigo por ano

Química (início de doutorado entre 2006 and 2015)

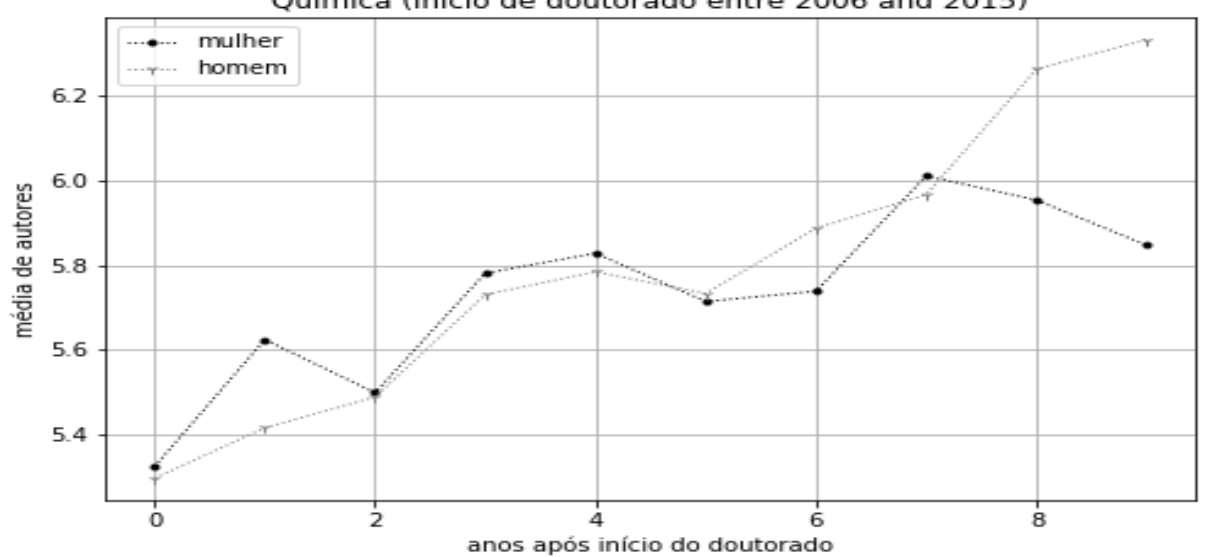

Fonte: Elaborado pelos autores.

Figura 26 - Média de autores por artigo de homens e mulheres por ano (Física)

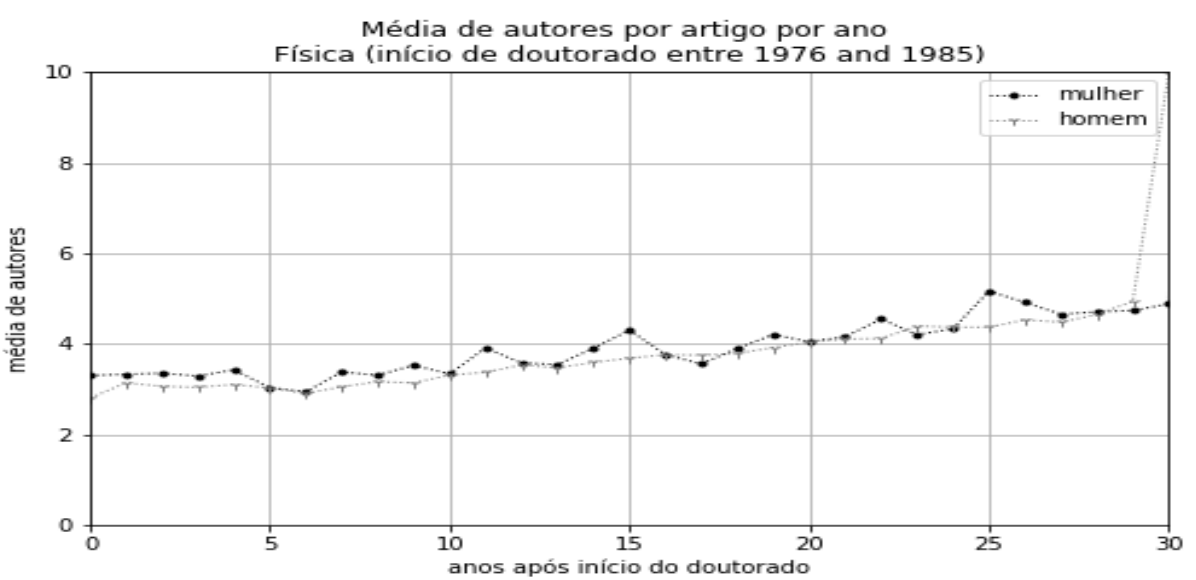

Fonte: Elaborado pelos autores. 

ciência: um estudo de caso da área de Ciências Exatas e da Terra no Brasil

Esteban Fernandez Tuesta, Luciano Antonio Digiampietri, Karina Valdivia Delgado e Nathália Ferraz Alonso Martins

Figura 27 - Média de autores por artigo de homens e mulheres por ano (Física)

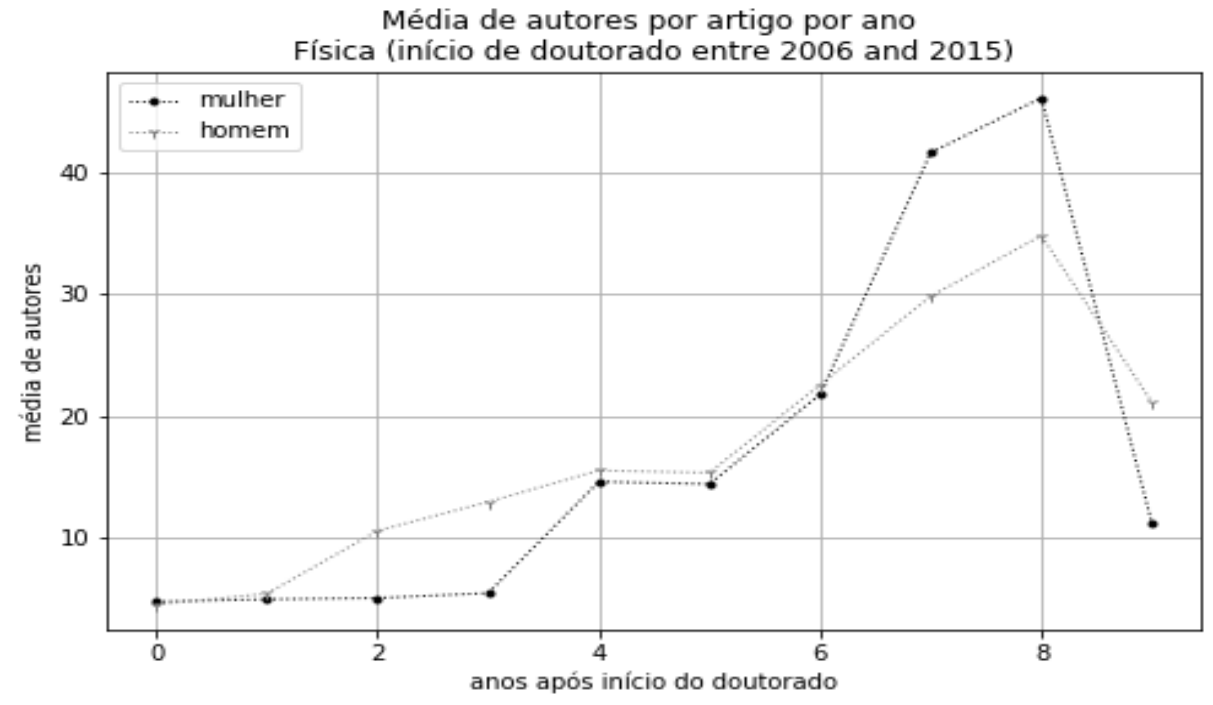

Fonte: Elaborado pelos autores.

\section{Conclusões}

Existe uma concordância geral entre pesquisadores da área de Ciência da Informação de que as publicações científicas são um dos indicadores de atividades de pesquisa tanto no volume quanto na qualidade. Em relação à presença das mulheres na investigação científica, estudos têm sido feitos por muitos autores, mediante o uso de ferramentas bibliométricas e estatísticas.

Neste trabalho, é analisada e comparada a produção científica de doutores e doutoras que atuam na área de Ciências Exatas e da Terra cujos currículos estão cadastrados na Plataforma Lattes. A validade dessa fonte de dados é conhecida pelo seu uso para fins de avaliação acadêmica e para outras atividades administrativas de reconhecida importância.

A análise de dados consistiu em agrupar os pesquisadores em cinco conjuntos de dez anos em relação ao início do doutorado. O objetivo desse agrupamento foi realizar comparações entre indivíduos com o mesmo tempo de participação em atividades de produção científica, o que conserva também as mudanças nos paradigmas temporais de produção e nos incentivos obtidos das instituições de origem ou dos programas de apoio e incentivo à produção 

ciência: um estudo de caso da área de Ciências Exatas e da Terra no Brasil

Esteban Fernandez Tuesta, Luciano Antonio Digiampietri, Karina Valdivia Delgado e Nathália Ferraz Alonso Martins

acadêmica dos estados ou do governo central. Esse método de separação e agrupamento foi utilizado por alguns dos autores deste trabalho em outros trabalhos da área.

Um dos resultados esperados e verificados foi o aumento da participação das mulheres em todas as subáreas das Ciências Exatas, tendo em alguns casos uma proporção equivalente à participação dos homens. Foi também constatado que, apesar do aumento da participação de mulheres na ciência (no caso, em Ciências Exatas e da Terra) e seu incremento na participação da produção de conhecimento científico (no caso publicações), ainda que pequenas, as diferenças entre participação e produção ainda persistem e são observadas desde o início da vida acadêmica, similar a estudos correlatos cujas causas são desconhecidas até o momento. É possível observar, por meio da distribuição de frequência das publicações, que a proporção dos homens é maior que a das mulheres, resultado esse similar a outros estudos já realizados para o cenário brasileiro.

Em resumo, foi encontrado que: (1) a participação de homens é consideravelmente maior que a de mulheres para quase todas as subáreas de Ciências Exatas e da Terra, com exceção de Química e Oceanografia; (2) existe um crescimento na presença das mulheres no cenário de pesquisa ao longo do tempo; (3) a porcentagem de publicações de mulheres é levemente inferior em relação à porcentagem de sua participação; (4) entre os hiperprodutivos, encontra-se uma maior proporção de homens; (5) o tempo médio de duração do doutorado tem diminuído para ambos os gêneros e, na última década, a diferença é quase nula; (6) o número de colaboradores para artigos escritos por homens ou mulheres é similar para todas as décadas com raras exceções.

\section{Referências}

ALONSO-ARROYO, A. et al. Análisis de género, productividad científica y colaboración de las profesoras universitarias de Ciencias de la Salud en la Comunidad Valenciana (2003-2007). Revista Española de Documentación Científica, Madrid, v. 33, n. 4, p. 624-64, oct./dic. 2010. 
AQUINO, E. M. L. Gênero e saúde: perfil e tendências da produção científica no Brasil. Revista de Saúde Pública, São Paulo, v. 40, n. especial, p. 131-132, ago. 2006.

ARRUDA, D. et al. Brazilian Computer Science research: gender and regional distributions. Scientometris, Hoboken, v. 79, n. 3, p. 651-665, July 2009.

BARRIOS, M.; VILLARROYA, A.; BORREGO, Á. Scientific production in psychology: a gender analysis. Scientometrics, Hoboken, v. 95, n. 1, p. 15-23, Apr. 2013.

BRAISHER, T. L.; SYMONDS, M. R. E.; GEMMELL, N. J. Publication success in nature and science is not gender dependent. BioEssays, Cambridge, v. 27 , n. 8 , p. 858-859, July 2005.

CAÑIBANO SÁNCHEZ, C.; BOZEMAN, B. Curriculum vitae method in science policy and research evaluation: the state-of-the-art. Research Evaluation, Guildford, v. 18, n. 2, p. 86-94, June 2009.

CESI, S. J. et al. Women in academic science: a changing landscape.

Psychological Science in the Public Interest, [S.1.], v. 15, n. 3, p. 75-141, Dec. 2014.

CONSELHO NACIONAL DE DESENVOLVIMENTO CIENTÍFICO E TECNOLÓGICO. Plataforma Lattes. Brasília: CNPq, 2018. Disponível em: <http://lattes.cnpq.br/>. Acesso em: 26 jan. 2018.

FERREIRA, L. O. et al. Institucionalização das ciências, sistema de gênero e produção científica no Brasil (1939-1969). História, Ciências, Saúde: manguinhos, Rio de Janeiro, v. 15, p. 43-71, jun. 2008. Suplemento.

FILIPPO, D. D.; CASADO, E. S.; GÓMEZ, I. Quantitative and qualitative approaches to the study of mobility and scientific performance: case study of a Spanish university. Research Evaluation, Guildford, v. 18, n. 3, p. 191-200, Sept. 2009.

KELLY, C. D.; JENNIONS, M. D. The h index and career assessment by numbers. Trends in Ecology \& Evolution, Oxford, v. 21, n. 4, p. 167-170, Apr. 2006.

LETA, J. Mulheres na ciência brasileira: desempenho inferior? Feminismos, Salvador, v. 2, n. 3, p. 139-152, set./dez. 2014.

KYVIK, S.; TEIGEN, M. Child care, research collaboration and gender differences in scientific productivity. Science, Technology and Human Values, New York, v. 21, n. 1, p. 54-71, 1996. 

ciência: um estudo de caso da área de Ciências Exatas e da Terra no Brasil

Esteban Fernandez Tuesta, Luciano Antonio Digiampietri, Karina Valdivia Delgado e Nathália Ferraz Alonso Martins

LEWISON, G. The quantity and quality of female researchers: a bibliometric study of Iceland. Scientometrics, Hoboken v. 52, n. 1, p. 29-43, Sept. 2001. MAULEÓN, E.; BORDONS, M.; OPPENHEIM, C. The effect of gender on research staff success in life sciences in the Spanish National Research Council. Research Evaluation, Guildford, v. 17, n. 3, p. 213-225, Sept. 2008.

PARENT IN SCIENCE. Entendendo a maternidade dentro do universo científico brasileiro. [S.1.]: Wix.com, 2018. Disponível em: <https://www.parentinscience.com/sobre-o-parent-in-science>. Acesso em: 20 jun. 2018.

R-PROJECT. The R Project for Statistical Computing. [S.1.]: The R Foundation, 2018. Disponível em: 〈http://www.r-project.org>. Acesso em: 20 jun. 2018.

SANDSTRÖM, U. Combining curriculum vitae and bibliometric analysis: mobility, gender and research performance. Research Evaluation, Guildford, v. 18 , n. 2, p. 135-142, June 2009.

SHELTZER, J. A.; SMITH, J. C. Elite male faculty in the life sciences employ fewer women. Proceedings of the National Academy of Sciences, Washington, v. 111, n. 28, p. 10107-10112, July 2014.

SYMONDS, M. R. et al. Gender differences in publication output: towards an unbiased metric of research performance. Plos One, San Francisco, v. 27, n. 1, p. 1-5, Dec. 2006.

TUESTA, E. F. et al. Analysis of advisor-advisee relationship: an exploratory study of the area of Exact and Earth Sciences in Brazil. Plos One, San Francisco, v. 10, n. 5, e0129065, p. 1-18, 2015.

WEBSTER, B. M. Gender in scientific production. Research Evaluation, Guildford, v. 10, n. 3, p. 185-194, Dec. 2001.

XIE, Y.; SHAUMAN, K. A. Sex differences in research productivity: new evidence about an old puzzle. American Sociological Review, New York, v. 63, n. 6, p. 847-870, Dec. 1998.

VALENTOVA, J. V. et al. Underrepresentation of women in the senior levels of Brazilian science. Peer Journals, London, v. 5, e4000, p. 1-20, Dec. 2017. 


\title{
Analysis of women's participation in science: a case study about the Exact and Earth Sciences area in Brazil
}

\begin{abstract}
In the last decades, several studies on women's participation in science have been conducted and are used to identify women's participation and production, as well as the basis for the development of scientific policies to encourage and value women in science. The present study evaluated the scientific production of more than 40,000 Brazilian PhDs who work in the area of Exact and Earth Sciences, and concluded that: (1) men's participation is considerably higher than women's in almost all the subareas analyzed; (2) there is a growth in the presence of women over time; (3) the percentage of women's publications is slightly lower than their percentage of participation.
\end{abstract}

Keywords: Women's participation in science. Scientific production. Exact and Earth Sciences.

Recebido: 06/02/2018

Aceito: 10/07/2018 